\title{
A Preliminary Study on the Teaching Model of College English Reading: Fragmented Reading
}

\author{
Ni Wang ${ }^{1}$ \\ ${ }^{1}$ Foreign Languages Department, Qingdao University of Science and Technology, Qingdao, China \\ Correspondence: Ni Wang, Gaomi Campus of Qingdao University of Science and Technology, Weifang, \\ Shandong, China. E-mail: wangni187536@126.com
}

Received: June 6, 2020

Accepted: July 8, $2020 \quad$ Online Published: July 23, 2020

doi:10.5539/ass.v16n8p91

URL: https://doi.org/10.5539/ass.v16n8p91

\begin{abstract}
English reading is of vital significance in English learning. In proficiency tests such as CET-4, CET-6, IELTS and TOFEL, extensive reading accounts for a large proportion in scores. Those who do well in reading tend to get higher scores. However, the current English teaching situation doesn't show its significance: the in-class time is limited with only two classes each week, and it's difficult to decide appropriate textbooks for teachers. As a result, students can't figure out the significance of extensive reading course and think little of it. Since the Internet appears in every aspect of our daily life, we can combine extensive reading course with the Internet. By using our spare time to reading fragmented information in English from the Internet selected and instructed by the teacher in any place, we bring fragmented reading into extensive reading teaching. In this paper, the author aims to assume a new teaching model concerning fragmented reading in details. Through this new teaching model, students can not only read English materials in classroom, but also after class in any place with their spare time. With much more input of English both in and out of class, their reading ability will be improved and they are more ready to deal with proficiency tests of all kinds. Meanwhile, students' interests will be aroused and their horizons will be broadened, which are also helpful for students to pass all kinds of proficiency tests.
\end{abstract}

Keywords: extensive reading, fragmented reading, teaching model

\section{The Importance of Extensive Reading}

As an important means of language input, extensive reading is significant in such aspects as acquiring knowledge, exchanging ideas as well as broadening horizons. Among the four basic abilities, listening, speaking, reading and writing, reading ability topped the other abilities. It is also one of the most important goals of cultivating students' overall ability. The syllabus of college English (2017) (hereinafter referred to as the syllabus) clearly stipulates that the purpose of college English teaching is to "cultivate students to have strong reading ability and abilities of listening, speaking, reading and writing, so that students can communicate freely with others in English". Meanwhile, some proficiency tests such as CET-4, CET-6, TEM-4, TEM-6, IELTS and TOFEL also demonstrate the importance of reading, which accounts for $40 \%$ in scores. Besides, English reading can also cultivate students' English sense, enlarge vocabulary as well as improve writing skill, etc. In all, English reading does help a lot in cultivating students' comprehensive ability of English, and it is a major and effective means of learning English well.

\section{The Problems of Current College Extensive Reading Teaching}

There are lots of problems concerning extensive reading course. On one hand, there are only two periods of extensive reading courses every week, which is far more enough compared to its importance. On the other hand, it's difficult to find an appropriate textbook covering various areas, including science, economy, politics, literature, culture, sports, health and so on. Students are easily to lose interest. Moreover, current textbooks are mostly out of date. In current English reading teaching, teachers give students certain period of time to do reading comprehensions, which are from texts on textbooks. Then answers are checked and explanations followed. Some key words and phrases, and difficult sentence structures will be underlined and explained. After class, they seldom have additional reading.

For students, they don't know why they have extensive reading class since they can't figure out the difference between extensive reading and intensive reading. In extensive reading classes, teachers explain not so much 
detailed as teachers in intensive reading classes, and reading skills don't really help them according to them. They feel they learn much more in intensive reading class. So what's the meaning of extensive reading class? Why do we have repeated course? This is one thing that students are confused about. For another thing, all teachers tell us reading is important, but what is the reason for that? There are only two classes each weak, and no additional reading materials are attached after class. Besides, the textbooks are too old-fashioned and boring, some of which originated from the 1990s, and students who are even younger than the books are not interested in them at all. Students, freshmen in particular, expect to improve their reading ability through the extensive reading course. However, at the end of semester, they are disappointed and the importance of English reading course fades. This course is dispensable in their opinion. It didn't get due attention from students.

As for teachers, selecting appropriate textbooks is a big headache every semester. Some are too easy which can't meet our teaching requirements, and some of them are too difficult, in which passages are too long beyond students' ability, and with the current class period, it's impossible to accomplish the goals. Furthermore, the textbook is just a small component of reading class. It's quite a dangerous thing if we just focus on a single textbook without additional reading materials attached. In the end, teachers have to compromise to choose a textbook which is not so satisfactory. Based on the current situation, teachers feel empty, regretful and anxious about students' reading development when they finish each class. English reading teachers are helpless.

Based on the problems stated above, the author thinks that to conduct extensive reading class is necessary and it's urgent to explore a new way of teaching extensive reading. With the new method of teaching, the author aims to improve students' reading ability to meet the demands of syllabus and proficiency tests.

\section{The Proposal of Fragmented Reading}

Under such circumstances, the author proposes a new way of English reading and teaching conforming to the era: fragmented reading. Since it's new, up until now only a few researchers have done some researches concerning the area. Chinese scholar Zhou Yina (2019) has given some strategies on fragmented reading teaching for college students (Zhou, 2019); another scholar Wang Zhuoqun and Chen Shuping (2020) talked about disadvantages and measures of fragmented reading for college students in the Internet Age (Wang \& Chen, 2020); the article of Cao Lihua and Liu Juan (2020) focuses on the influence of mobile fragmented learning on College Students' English Reading Ability (Cao \& Liu, 2020); Yuan June and Wang Chengxia (2018) do an empirical study on the application of fragmented reading in college English teaching (Yuan \& Wang, 2018); Zhao Shuhai (2020) analyzes the advantages and disadvantages of college students' mobile phone fragmented reading (Zhao, 2020). Based on the researches Chinese scholars have done, the author proposes the new model of English reading teaching by taking practical factors of author's university into consideration.

What is fragmented reading? Different scholars have different versions of its definition. In Cao's article (Cao \& Liu, 2020), she concludes some scholars' opinions about fragmented learning: According to Wang Chengbo et al., fragmented learning refers to the process in which learners process, absorb and store meaningful knowledge fragments from the Internet by using fragmented reading or in the fragmented time. It emphasizes that fragmented learning is a process of knowledge construction by using fragmentary time and content. Zhang Keyong summarized the concept of fragmented learning as follows: learners learn online information in fragments at will, anytime and anywhere in their daily life through any media, and such learning way of getting information bit by bit is called network fragmented learning. Similarly, Wang Mi emphasizes the dispersion of learning content, the fragmentation of time, the distribution of space and the diversity of media in fragmented learning, and conducts fragmented learning anytime and anywhere according to the needs of learners. Professor Wang Zhuli defines the fragmented learning in a narrow sense and a broad sense. In the broad sense, fragmented learning refers to formal and informal learning conducted by learners using fragmented time, resources and media, while in the narrow sense, fragmented learning is limited to informal learning. Different from formal education or formal learning, scholars emphasize that fragmented learning is a kind of informal learning (Cao \& Liu, 2020). Definitions that the scholars above give have common ground, that is, fragmented learning is characteristic of fragmented contents, time and place from the Internet according to the needs and interests of learners.

In the author's opinion, fragmented reading takes phones, ipads, computers, etc as the main media and students read English materials through websites, subscriptions or e-books in their spare time in any places they like in addition to daily work and formal in-class learning. Besides courses they have to attend to, students can make use of the spare time, for example, time they stand in the line, time they take a vehicle. They can also do it in any place, as long as there is an Internet connection, for instance, in the waiting room when you wait for the train or bus to come, in the bathroom, etc. Instead of watching TV series or movies, they can read English materials to 
form a good habit of reading English.

Since reading is important and not enough time allotted to the course, we have to spend enough time on reading after class. At present, people rely too much on Internet to do things, and students spend a lot of time on the Internet to do something they are interested in. Why can't we make good use of the Internet by combining it with English reading? Students can choose materials they like, which also keep up with the time. Teachers can make some assignments and ask students to finish tasks everyday. Unconsciously, students' reading ability improves and enough reading materials are input. It should be noted that during the course, teachers should conduct some activities to share their reading materials or discuss what they have read to encourage more students to engage in reading of this kind more positively. In this way, college English reading class is enriched and reading teachers feel full and hopeful for students. Students are likely to be interested in and put more emphasis on the reading course.

With science and technology develops, almost every students have access to the Internet by using phones, computers, ipads to surf websites, apps or subscriptions. They can also use wireless equipment to chat and share information with each other. This is very convenient for teachers to assign tasks and students to finish. All above make the new teaching model possible and feasible.

\section{The Theoretical Basis of the Proposal of Fragmented Reading}

There are some theories to support the author's proposal, to verify the author's assumption is possible and feasible. Basically, there are three aspects of theories.

\section{(I) Fragmentation and fragmented reading}

Fragmentation was first proposed in the 1980s by "postmodernist researchers". It came into being as the coexistence of multiple ways of thinking or action in the society. Just as Professor Yu Guoming said, due to the rise of mobile assistance technology and the proliferation of media, fragmented reading has become one of the main ways of mass communication (Zhou, 2019).

Fragmented reading mainly takes mobile phone software, various electronic devices and other electronic terminals as the main carrier, and users read things from websites, subscriptions and e-books, etc to get information to enrich themselves, which is a new kind of reading mode.

Research shows that appropriate fragmented reading can not only enhance college students' interest in English reading, but also increase the amount of reading input, which is very important in English reading. With teachers' instruction, students who persist for a long time will definitely make great process in comprehensive ability in English, let alone the English reading ability.

\section{(II) Multi-Mode and Mobile Assistance Technology (MALL)}

Multi-Mode in a broad sense refers to the diversity of information presenting, including pictures, texts, videos, etc., as well as the way human senses (such as seeing, listening) interacting with the external environment, etc. The theory of multimodal cognition holds that multimodal teaching can effectively promote students' cognition and learning by using different ways of information presenting. Fragmented reading can be conducted by means of mobile assistance technology and there are lots of modes concerning it, so it becomes a major medium for fragmented reading. Mobile assistance technology is a medium that enables learners to learn "anytime", "anywhere" through mobile devices. Compared with computer assistance (CALL), it is more interactive and personalized. Technically, mobile assistance technology combines texts with pictures, audio, video and other modal contents, which will greatly attract students' attention, especially students who were born around or after the year of 2000. Meanwhile, mobile assistance technology supports editing, grouping, massage sending, information sharing, etc., which is also attractive and personalized for college students nowadays. The rise of mobile assistance technology has provided a brand new platform for reading. With the mobile assistance technology, students can get large amount of information and contents input, as well as interaction with others. The mobile assistance technology becomes a more effective tool for English teaching and plays an increasingly important role in college students' English learning.

\section{(III) The Policy from the Country}

The Outline of the National Plan for Medium and Long-term Education Reform and Development (2010-2020) states that "students should be encouraged to take the initiative to learn and study independently by means of information, and enhance their ability to analyze and solve problems by using information technology". The Ten-year Development Plan of Educational Informationization (2011-2020) issued by the Ministry of Education in 2012 proposed to promote the integration of information technology and teaching and improve 
informationization education learning level. In the information age, with the popularity of social software such as weibo and WeChat, fragmented reading has become an inevitable trend in today's society.

\section{The Advantages of Fragmented Reading}

Besides the necessity and feasibility to implement new model of teaching, there are also many advantages of fragmented reading.

First, students can read at any time in any place, and this breaks out the limitation of time and space. Students don't need to study in the classroom or library or during the class time. This is very flexible for both students and teachers.

Second, students can select reading materials they have an interest in with teachers' supervision. In traditional teaching, students have to focus on the textbooks and they don't have much freedom to choose what they like. Furthermore, contents in textbooks are not so in fashion, and students don't have much interest in them. In the new teaching model, the reading materials are usually the ones that keep up with time, and this is very important for students who were born around the year of 2000. Besides, students can be input enough reading materials through fragmented reading. Since in current course, they are only exposed to readings from textbook, which are very limited and incomplete in contents. Current proficiency tests require students equipped with knowledge of all fields, and more and more reading comprehensions in those tests are from some very timely news websites on the Internet, which shows that it is not enough to focus on textbooks and give no attention to other resources. The new teaching model gives us the opportunity to read timely materials from the Internet thanks to fragmented reading.

Third, students can also enjoy multimedia such as pictures, sounds and animations to spark their interest. In traditional teaching, students are only exposed to written forms and teachers' explanations. It's very easy for students to lose interest in or be distracted from the course. They seldom have the opportunity to look at pictures in color, listen to sounds or watch some animations. In this new way of teaching, the author believes that students will have more interest in extensive reading class, and their reading ability will be improved subconsciously.

\section{The Assumption of a New Teaching Model: College English Fragmented Reading}

\subsection{How to Implement the New Teaching Model}

Based on the problems of current way of teaching reading and advantages of fragmented reading, we combine the new teaching model: fragmented reading with college English reading class. Teachers should provide resources online for students and assign them homework everyday based on topics. Enough input should be guaranteed, and some ways of supervision should be implemented, since this fragmented reading should be conducted mainly after class. During the class, besides finishing reading materials in the textbook, teachers should spend certain period of time to explain and check the readings during the fragmented time. Other measures should also be taken to make the model more effective and have more students engaged in.

To figure out whether the model is effective or not, we can do an experiment. We take a whole semester as a unit. One teaching class belongs to experimental group, another control group. At the beginning of a semester, students of two groups should take part in the same exam. Their scores should be recorded. Throughout the whole semester, teachers employ new English teaching model, that is, combining fragmented reading into current course, and in control group, traditional teaching method is used. At the end of the semester, another exam with higher level of difficulty compared to the one at the beginning of the semester will be conducted. Scores of two groups should be recorded. We compare scores of two groups before and after the employment of new reading teaching to decide whether the model is effective or not.

\subsection{The Result of the Experiment}

With the new teaching model, we hold the opinion that the new teaching model is effective based on the following reasons: first, enough information in English will be input since the more students are immersed in English, the more they can get, and they will improve a lot in English. Second, the reading materials online keep up with time, which will attract students' attention very much, since the contents of current textbook are mostly out-dated and it's difficult to make them focus on. Students may feel boring in the reading class and get nothing through course. In the end, they won't place much emphasis on the reading course. Third, students can conduct this type of reading at any time in any place, which is very convenient. They can use their spare time to read anything in English they like in any place, which make them use time more efficiently. Fourth, this is an information era, and the internet and phones are available to every student. They spend a lot of time on internet every day doing entertaining and interesting things, such as reading novels, shopping, chatting, listening to music, 
watching movies, which is actually to a great extent a waste of time. We can instruct students to make use of the time to do other interesting things, such as reading interesting things in English. This will be not only entertaining, but improve their English reading ability. Finally, more and more proficiency exams such as CET-4, CET-6, IELTS, TOFEL pose greater challenges for students to know wide ranges of knowledge. Fragmented reading provide students opportunities to read widely and learn as much information as possible concerning different fields, which lays a solid foundation for students to pass important proficiency exams.

Based on the reasons stated above as well as the theoretical basis of fragmented reading, we think it is worthwhile to try the new teaching model, and make the reading class count.

\section{Conclusion}

All through the time, reading is considered important, which is embodied in major exams of all kinds at home and abroad. However, the teaching process in practice doesn't show its significance, since the in-class time is very limited. Moreover, textbooks are too old-fashioned and contents are too single, which won't spark students' interest, especially college students nowadays. Besides, the current teaching model makes the input not enough since students and teachers only focus on the textbooks, which is a very dangerous practice in extensive reading class. Gradually, students lose their interest in reading class, and they won't place much emphasis on extensive reading class. Based on problems college reading teachers and students encounter, we have strong reasons to explore and implement a new teaching model of English reading. Coherent to the development of new era, more and more people are getting access to the internet. We can combine the internet with our extensive reading course to improve students' reading ability, which is very important different types of exams, because in these exams reading tops the list in its importance. Through fragmented reading, students with a phone can conduct the reading at any time in any place, which also helps them to form a good habit of reading English. The author holds the opinion that it's very worthwhile to try the new teaching model and it will be very successful, which is meaningful for not only students and teachers but also for the whole reading teaching prospects.

\section{References}

Cao, L. H., \& Liu, J. (2020). Influence of Mobile Fragmented Learning on College Students' English Reading Ability. Information Literacy, 3, 119-120. https://doi.org/10.16681/j.cnki.wcqe.202005060

Chai, Y., \& Qi, W. P. (2014). The influence of the Change of College Students' Reading Style on their Learning in the Internet Era. Ideological and Theoretical Education, 8, 109-112.

Wang, Z. Q., \& Chen, S. P. (2020). disadvantages and measures of fragmented reading for college students in the Internet Age. Beijing Education, 5, 61-63.

Yuan, J. E., \& Wang, C. X. (2018). Empirical Research on the Application of Fragmented Reading in College English Teaching. Basic Education, 12, 112-113.

Zhang, J. M. (2019). Research and Application of Adaptive Recommendation of Learning Resources in fragmented English Reading (Master's thesis, Yunan Normal University, Yunan, China). Retrieved from http://oversea.cnki.net/Kcms/detail/detail.aspx?dbcode=CMFD\&dbname=CMFD2020\&filename $=1019922$ 719.nh

Zhao, S. H. (2020). Advantages and Disadvantages of College Students' Mobile Phone Fragmented Reading. Higher Education, 15, 22-24.

Zhou, Y. N. (2019). Research on Fragmented Reading Strategies for College Students. Journal of Taiyuan City Vocational And Technical College, 4, 146-147. https://doi.org/10.16227/j.cnki.tycs.2019.0299

\section{Copyrights}

Copyright for this article is retained by the author(s), with first publication rights granted to the journal.

This is an open-access article distributed under the terms and conditions of the Creative Commons Attribution license (http://creativecommons.org/licenses/by/4.0/). 